\title{
Development of student knowledge in competence-based pre-vocational secondary education
}

\author{
Maaike Koopman $\cdot$ Peter Teune $\cdot$ Douwe Beijaard
}

Received: 20 January 2009/Accepted: 14 August 2009/Published online: 2 December 2011

(C) The Author(s) 2011. This article is published with open access at Springerlink.com

\begin{abstract}
The purpose of this study was to gain insight into the development of student knowledge in pre-vocational secondary education schools which differ in the manner and extent to which they have implemented characteristics of competence-based education. The implementation of these characteristics was examined using a teacher questionnaire and the development of knowledge was investigated using concept mapping. The results showed that students developed slightly more knowledge in learning situations with fewer characteristics of competence-based education. The organisational characteristics of the learning situations were further found to be distinctive for the development of knowledge.
\end{abstract}

Keywords Competence-based education - Concept mapping · Knowledge development . Vocational education

\section{Introduction}

This research focused on the development of student knowledge within the context of recently-developed (competence-based) learning environments in Dutch pre-vocational secondary education (PVSE). There were several reasons for conducting this study. First, during the last decades, learning environment research has grown considerably (Fraser 1998). The context in which learning occurs and through which learning outcomes are affected has been mainly investigated in regular secondary education and in primary education. Much less attention has been paid to the context of vocational education. For

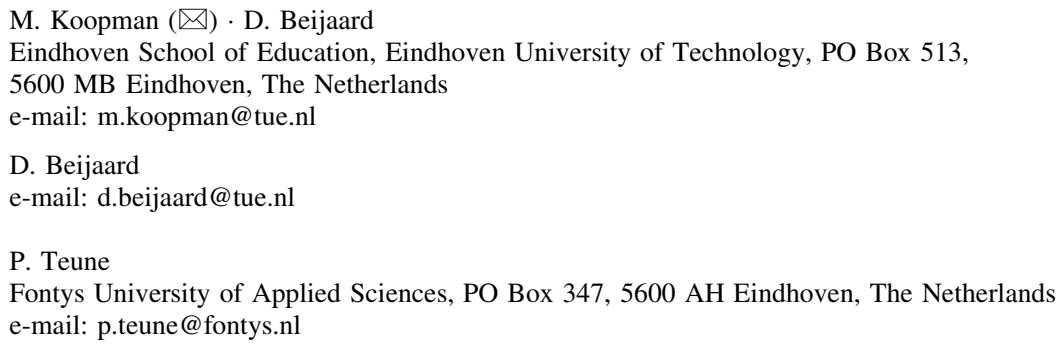


example, scanning the content of 11 volumes of the Learning Environments Research journal showed that, out of more than 150 articles, 21 articles contained the word 'vocational', whereas only seven of these articles actually dealt with studies in the context of vocational education and/or with vocational learning. Because large numbers of students attend schooling in vocational education, the role of the learning environment in this context deserves more attention. Second, research into learning environments has often focused on the relation between motivational aspects of learning or student achievement and students' perceptions of the learning environment (Fraser 1998; Telli et al. 2007; Wubbels et al. 2006). The development of knowledge, especially outside traditional subject areas such as science or mathematics, has been scarcely investigated.

We chose to focus on the particular context of The Netherlands for specific reasons. In The Netherlands, around $60 \%$ of children between 12 and 16 years of age attend prevocational secondary education schools. PVSE curricula in The Netherlands differ in the degree of difficulty (four levels running from basic to theoretical are distinguished) and in the ratio of theoretical to practical subjects. Furthermore, PVSE in The Netherlands encompasses programs in the four sectors of Care and Welfare, Technology, Business and Agriculture. Currently, students in Dutch schools for PVSE are increasingly being confronted with different forms of competence-based learning environments largely based upon social constructivist conceptions of learning. The focus of learning in such environments is on the development of competencies which are supposed to integrate knowledge, skills and attitudes (Eraut 2004; Guile and Young 2003). Some schools have advanced strongly in their development of competence-based education, while others have only implemented a few elements as yet. This opens up opportunities for studying the effects of non-traditional learning environments (Fraser 1998).

Competence-based PVSE schools generally strive to create powerful learning environments that aim for students to work on complex and challenging learning tasks and to develop problem-solving and collaborative learning skills (De Corte 2003; Könings et al. 2005; Merrill 2002). In such environments, the manner in which the process of active construction and integration of knowledge, skills and attitudes is guided appears to be important (Kirschner et al. 2006; Van Merriënboer and Paas 2003). In research on learning environments, characteristics of these environments often are classified into dimensions which typically constitute a dimension concerning the content and organisation of the environment and a dimension concerning the interaction between persons (e.g. Moos 1979; Watzlawick et al. 1967). In this study, characteristics of powerful learning environments were operationalised in similar dimensions, using the classification of De Bruijn et al. (2005), consisting of a content dimension and a guidance dimension. The content dimension concerns the manner in which learning content is dealt with in the learning environment. The guidance dimension concerns the different types of student guidance provided by teachers, such as modelling or the provision of feedback. The advantage of the dimensions discerned by De Bruijn et al. (2005) is that these were originally developed for competence-based learning environments in vocational education.

Competence-based education is assumed to foster the development and integration of knowledge, skills and attitudes. Learning skills and attitudes occupy a more central position in competence-based education than in traditional education. However, the construction of knowledge still remains an important objective for students to become qualified professionals. That is, knowledge is an essential component of competence and necessary to make adequate decisions under different circumstances (Eraut 2004; Van der Sanden 2004). As can be concluded from the first paragraph, little is known, however, about the effects of learning environments on the actual knowledge development of PVSE 
students in general and those in non-traditional (competence-based) learning environments in particular. The central question in the present research was therefore: What is the relation between the development of PVSE students' knowledge and characteristics of competence-based learning environments? The answer to this question could contribute to better understanding of the development of student knowledge in PVSE schools, which differ in the extent to which and manner in which they implement the characteristics of competence-based education. The extent to which the learning environment can be considered competence-based is expected to have a positive influence on the development of student knowledge. For example, the implementation of characteristics of competencebased education has been found to positively affect students' self-regulated learning (De Bruijn et al. 2005), development of skills and remembering acquired knowledge (Dochy et al. 2003) and deeper learning (Blumberg 2000). In this study, the elaborateness and organisation of the students' knowledge were of particular interest as these aspects of students' knowledge have been found to be indicative of the quality and development of their knowledge (Scardamalia and Bereiter 2006).

\section{Knowledge development in competence-based education}

Knowledge development

Competence-based education involves meaningful learning, which involves students in relating learning content to their own personal interests and goals. That is, meaningful learning (Ausubel 1968; Trigwell and Prosser 1991) involves the conscious integration of new knowledge into the knowledge which the learner already possesses (Novak 2002). Such integration surpasses rote learning which merely involves the more or less arbitrary incorporation of unchanged new information into existing cognitive structures (Novak 2002). In contrast to rote learning, meaningful learning can promote the further development of knowledge (Novak 2002; Pintrich et al. 1993). The construction of knowledge involves concepts being related to each other and new concepts being integrated into existing knowledge structures in a conscious and logical manner.

Research on learning environments and school effectiveness research is generally oriented towards investigating the quantity of students' knowledge. In this study, however, attention was paid to the development of the quality and structure of students' knowledge. Regarding the quality and structure of knowledge, the elaborateness of student knowledge and the way in which this knowledge is organised are important (Liu 2004; Sweller and Sweller 2006; Vosniadou 2007). The development of knowledge is essential for a student to become a competent beginning professional, and it is expected that meaningful learning and the development of knowledge are effectively promoted by competence-based education (Biemans et al. 2004; Gulikers et al. 2005). Learning situations with competence-based characteristics are supposed to be powerful and thereby elicit knowledge construction. This could be accomplished, for example, via the integration of related subject areas, the adoption of authentic situations as the starting point for knowledge construction and the creation of room for student input. In schools which have adopted such characteristics, students are also likely to organise that which is learned in a different manner. For example, that which is learned in competence-based learning situations can be linked to real-life working situations and go beyond direct school subject matter more than in traditional learning situations, because the learning content is more relevant for the students to start with (Van der Sanden 2004). 
Competence-based learning environments

Characteristics of competence-based learning environments are of critical importance for the promotion of meaningful learning and the development of knowledge. In learning environments research, dimensions that influence learning are often distinguished (Moos 1979; Watzlawick et al. 1967) and, because of the innovative character of competencebased education, it is important that proper attention is paid to the influence of these dimensions and accompanying characteristics. In prior research by De Bruijn and Overmaat (2002) and De Bruijn et al. (2005), a content and a guidance dimension of competence-based learning environments were used to describe the degree to which learning environments in Dutch vocational education could be considered powerful. The content and the guidance dimensions each consist of several components.

De Bruijn et al. divide the content dimension into four components along which schools can differ: the actual subject matter (e.g. authenticity of the subject to be studied, integration of subject areas, tasks which resemble professional practice, learning-to-learn); the structure and range of the subject matter (e.g. the adoption of competencies and authentic situations as the starting point for the learning and practice of knowledge and skills); the delivery of the subject matter (e.g. use of a mixture of teaching methods, different sources of information, input from students, interaction with students); and forms of processing for the subject matter (e.g. active learning, exploratory learning, reflective learning) (De Bruijn and Overmaat 2002; Schelfhout et al. 2006; Sluijsmans et al. 2008; Wesselink et al. 2007). The guidance dimension concerns: characteristics of the systematic guidance provided by teachers, experts and peers; the guidance, clarification and promotion of the student learning trajectory via a fixed program order; the provision of guidance aimed at the learning of skills; and the guidance of learning processes using different forms of guidance (e.g. instruction, demonstration, thinking aloud, allowing autonomous student work, active support, scaffolding, provision of help when necessary, evaluation, feedback) (De Bruijn and Overmaat 2002; Entwistle and Peterson 2004; Schelfhout et al. 2006; Van Grinsven and Tillema 2006).

De Bruijn translated these dimensions into a questionnaire with scales consisting of items belonging to the content and guidance dimensions. Three content scales were distinguished, namely, Type, Power and Customary (De Bruijn and Overmaat 2002; De Bruijn et al. 2005). The Type scale reflects the degree to which the organisation of the learning situation can be typified as potentially powerful in terms of the four components of the content dimension of competence-based education. The Power scale reflects the degree to which those components considered powerful in advance were actually realised in the particular learning situation. The Customary scale reflects the extent to which less powerful characteristics are present in the organisation of the relevant learning situation and, as such, can be considered a control variable. For the guidance dimension, three scales were distinguished, namely, Strong Guidance, Total Guidance and Growth (De Bruijn and Overmaat 2002). Strong Guidance reflects the provision of systematic guidance, structured learning routes and the tools which students need to perform the necessary tasks. Total Guidance reflects the nine different forms of guidance which could be provided during the student's education. Growth reflects the provision of relatively more guidance in the later years of a student's education than in the initial years, and is calculated as a difference score (degree to which the nine forms of guidance were used in students' later years minus degree to which the nine forms of guidance were used in students' first years). Analysis of the data by De Bruijn et al. resulted in a classification of the schools across the dimensions, with three types discerned: schools scoring above average on both dimensions; schools 
scoring below average on both dimensions; and mixed schools scoring high on one but low on the other dimension. Results of the study by De Bruijn et al. showed that only a few learning environments of the participating schools could be described as strongly competence-based (De Bruijn and Overmaat 2002). Ambiguous relations between learning environments characteristics, motivation and course results were found (De Bruijn et al. 2005). For example, some learning environment characteristics had a negative influence on student motivation whereas others had the expected positive influence. However, the dimensions and accompanying scales did have a positive influence on student progress (De Bruijn et al. 2005).

Reliability analysis resulted in Cronbach alpha coefficients of between 0.55 and 0.85 . (Except for the Strong Guidance scale, every scale had sufficient reliability.) Analysis for construct validity showed that the content dimension scales of Type and Power correlated positively and that negative significant correlations were found between both the Type and Power scales and the control variable Customary. The guidance dimension scales of Strong Guidance and Growth were also positively related.

In this study, the instrument of De Bruijn was used to describe and classify the learning environments. In accordance with other research into learning environments, perceptions of the learning environment were used to investigate its characteristics (De Bruijn and Overmaat 2002; De Bruijn et al. 2005). In this research, teachers' perceptions of the learning environment that they created were used because relatively new learning environments were investigated. Therefore, it was expected that students would not be very capable of judging a situation to which they were not accustomed yet.

Measuring development of students' knowledge

In order to measure the development of students' knowledge in terms of elaborateness and organisation, a suitable research method had to be selected for the present study. Knowledge is often measured using tests (Linn et al. 1991). An alternative method is concept mapping, which is typically used for knowledge elicitation in groups (e.g. as a tool for brainstorming by professionals or other experts), as a learning strategy (e.g. as an aid for studying or writing structured texts) or as an instrument for assessment and diagnosis (Akinsanya and Williams 2004; Budd 2004; Buzan 1991; Trochim 1989). Concept mapping can also be used for visualising the organisation of people's knowledge and the elaborateness of this knowledge (cf. Akinsanya and Williams 2004; Boekaerts and Simons 2003; Novak 2002). Similarly, the development of learners' knowledge can be investigated and evaluated across a given time span using concept maps. Concept maps consist of knowledge in terms of concepts and the relations or links between those concepts (Novak 2002). When analysing concept maps, attention can thus be paid to the number of nodes and links, the relevance and relative importance of the concepts in the maps, the types of connections between the concepts, the depth (i.e. number of layers) in the maps and the general content of the maps (i.e. clusters of concepts) (Liu 2004; Mavers et al. 2002; RuizPrimo et al. 2001). These features provide information on the quality of knowledge regarding a particular topic and appear to be well-suited for the measurement of PVSE students' knowledge over time. The elaborateness and organisation of student knowledge can be investigated by means of concept mapping, allowing for measurement separate from context or school type, which would not be possible using traditional tests.

In research on learning environments and school effectiveness, the development of students' knowledge has been found to be influenced by not only the learning environment 
but also by gender, age and prior knowledge. Girls often demonstrate greater knowledge development than boys (Van Langen et al. 2006). Studies in the field of developmental psychology also show that age affects the learning process and the degree of knowledge elaboration and organisation (Gathercole 1998). Those students with greater prior knowledge also have been found to perform better when such learning outcomes as the elaboration and organisation of knowledge are measured (Boekaerts and Simons 2003). This can cause differences between students within PVSE. Although little research has been conducted into the development of knowledge of PVSE students, their prior knowledge certainly can differ across PVSE sectors and programs.

Based on the theoretical framework, we can now formulate more specific research questions:

- How do the learning environments as perceived by teachers and classified in three types (above average, below average and mixed) relate to the development of student knowledge in PVSE?

- How do the content and guidance dimension of competence-based education as perceived by teachers relate to the development of student knowledge?

- How do the background variables of age, gender, sector and program relate to the development of student knowledge?

\section{Methods}

Participants and context of the study

Dutch PVSE consists of four programs in four sectors. As described earlier, the four programs differ in their degree of difficulty and in the ratio of theoretical to practical subjects. For example, in the basic vocational program (the most practice-oriented program), students mainly follow vocational subjects at a basic level of difficulty. In the combined and theoretical programs (the more theoretical oriented programs), students are mainly engaged in general subjects at a higher level of difficulty. The difficulty of the middle management vocational program is in between that of the basic and the combined programs.

A convenience sample across different PVSE programs in the south of The Netherlands was selected based on the schools having elements of competence-based education. The students involved in the study came from either the Care and Welfare or Technology sectors and from different learning situations $(n=14$; see Table 1). All learning situations in this study involved a new project or topic studied over a period of several weeks. One shared aspect of all learning situations was that attention was paid to the development of knowledge. Knowledge and the concepts relevant to general education subjects (e.g. mathematics, geography) played an important part in all of the situations. Another shared aspect of all situations was that a core concept could be distinguished and thus provide the basis for the construction of a concept map by the students. All of the situations lasted for about 25 hours of scheduled education across a period of 8-10 weeks.

Students $(N=812)$ participating in the present study were in the first, second or third year of PVSE. The PVSE students came from different programs which varied from mainly practice-oriented to mainly theory-oriented. Two groups of students (64 of the 812 students) were also included from the first or second year of Vocational Education and Training (VET; secondary vocational education) in order to examine the possible 
Table 1 Participants involved in the study

\begin{tabular}{llllr}
\hline $\begin{array}{l}\text { Learning } \\
\text { situation }\end{array}$ & Year & Sector & Program & $\begin{array}{c}\text { Number of } \\
\text { students }\end{array}$ \\
\hline A & $1+2$ & Technology & Both practice and theory-oriented & 49 \\
B & 1 & Technology & Mainly practice-oriented & 41 \\
C & 2 & Technology & Mainly theory-oriented & 17 \\
D & 2 & Care \& Welfare & Mainly practice-oriented & 114 \\
E & 2 & Care \& Welfare & Mainly practice-oriented & 14 \\
F & $1+2$ & x & Both practice and theory-oriented & 103 \\
G & 2 & X & Both practice and theory-oriented & 205 \\
H & 3 & Technology & Mainly practice-oriented & 14 \\
I & 3 & Care \& Welfare & Mainly practice-oriented & 34 \\
J & 3 & Care \& Welfare; x; x & Mainly practice-oriented; mainly theory- & 66 \\
& & & oriented; mainly theory-oriented & 62 \\
K & 3 & x & Mainly theory-oriented & 29 \\
L & 3 & x & Mainly theory-oriented & 22 \\
M & 1 & VET Technology & Level 4 & 42 \\
N & 2 & VET Technology & Level 2 & \\
\hline
\end{tabular}

a VET Vocational Education and Training; PVSE prepares students for VET training

$\mathrm{x}=\mathrm{In}$ this school, no sector had to be chosen in the year the students were in

differences between PVSE and VET students (i.e. students of different levels). Some of the first- and second-year students had not chosen a sector as yet as this simply was not possible in their school; this is indicated with an $\mathrm{x}$ in Table 1. Teachers involved in the investigated learning situations participated voluntarily in the study. All teachers had more than three years of teaching experience and were involved in the development of tasks in the learning situations. Although all teachers responded, some students didn't respond because of absence, illness or incomplete data. In subsequent multilevel analysis, missing values were replaced with estimates using the missing values analysis command in SPSS (Trautwein and Lüdtke 2009).

\section{Data collection}

Two types of data were collected: information regarding the learning situations; and information regarding the development of knowledge. The development of student knowledge was investigated using concept mapping. A pretest and a posttest were administered in order to compare the quality of students' concept maps and knowledge across a period of 8-10 weeks in which they were involved in a particular project. Prior to pretesting, a questionnaire was administered to the teachers to obtain information about the extent to which and manner in which characteristics of competence-based education were implemented by them.

\section{Learning situations questionnaire}

Because learning situations could differ in the degree to which they involve elements of competence-based education, we administered a questionnaire in which teachers, also involved in the development of the learning situation, were asked to describe the manner in 
which the education was organised (De Bruijn et al. 2005). The procedure developed by De Bruijn et al. (2005) was followed for the scales, dimensions and the identification of types of learning environments. The questionnaire contained items about the two dimensions consisting of characteristics of competence-based education. More specifically, the questionnaire consisted of four groups of three questions each regarding one of the four components of the content dimension of competence-based education and one group of three questions regarding the guidance dimension. For the content components, each time a series of three related elements of competence-based versus three related elements of more traditional forms of education were mentioned, the respondents had to indicate (a) which of the two series of descriptions was preferred, (b) which of the two series of descriptions best fitted the current learning situation and (c) the extent to which the mentioned elements were present in the current learning situation (see Fig. 1 for an example). Respondents had four answering options for each of the content items with respect to preferred or actual situation: (1) closer to the first than to the second series of statements, (2) closer to the second than to the first series of statements, (3) completely according to the first series of statements, and (4) completely according to the second series of statements. A three-point scale was constructed for the subquestions asking for the degree to which each of the statements in the series was true for the current situation (question c): Not at all, To some degree or To a large degree. Based on all these questions, three content scales were constructed, namely, Type, Power and Customary (see the section on competence-based learning environments). The scales provide information about the degree to which the content components are implemented in the learning situations.

The group of three guidance elements concerned the systematic guidance provided while the students learned independently. Respondents had to indicate for one item containing two series of three statements (a) which of the two descriptions was preferred,

Fig. 1 Sample questions related to the component of the actual subject matter ${ }^{\text {a }}$
The actual subject matter

\begin{tabular}{|c|c|c|c|c|}
\hline \multicolumn{3}{|c|}{$\begin{array}{l}\text { A } \\
\text { 1. An emphasis on functional } \\
\text { and authentic learning } \\
\text { 2. A curriculum arranged around } \\
\text { situations and actions occurring } \\
\text { in professional practice } \\
\text { 3. Explicit attention to learning } \\
\text { skills and problem solving }\end{array}$} & \multicolumn{2}{|c|}{$\begin{array}{l}\text { B } \\
\text { 1. A curriculum divided into } \\
\text { clear-cut parts of course } \\
\text { material } \\
\text { 2. Theory and general skills ar } \\
\text { dealt with separately } \\
\text { 3. A focus on training } \\
\text { instrumental skills }\end{array}$} \\
\hline a & \multicolumn{4}{|c|}{ 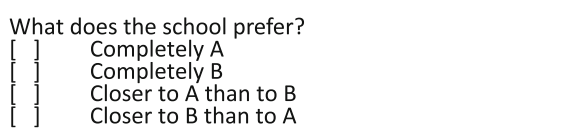 } \\
\hline$b$ & \multicolumn{4}{|c|}{ 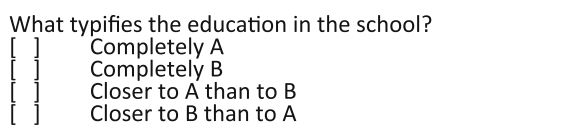 } \\
\hline c & \multicolumn{4}{|c|}{$\begin{array}{l}\text { To what extent are the elements present in the current } \\
\text { learning environment? }\end{array}$} \\
\hline & Not at al & \multicolumn{2}{|c|}{ To some degree } & To a large degree \\
\hline $\begin{array}{l}\text { A1 } \\
\text { A2 } \\
\text { A3 } \\
\text { B1 } \\
\text { B2 } \\
\text { B3 }\end{array}$ & & & & \\
\hline
\end{tabular}


(b) which of the two descriptions best fitted the current learning situation and (c) the extent to which the elements mentioned in the descriptions were present in the current learning situation. Answering options were similar to those for the content dimension items. An additional 18 items addressed the extent to which nine forms of guidance distinguished by De Bruijn et al. (2005; also see Introduction) were used. Using a five-point scale (from Almost never to Very often), teachers were asked to judge the extent of provision of guidance during the first years ( 9 items) and the final years of PVSE (9 items). (Examples of items are: "Do teachers coach the students' learning process?" or "Do teachers evaluate the students' learning process?") From these guidance items, three guidance scales were constructed, namely, Strong Guidance, Total Guidance and Growth. These scales provided information about the type and frequency of guidance provided by teachers in the learning situations.

\section{Concept maps}

In order to investigate the development of student knowledge, the participants were involved in a pretest and a posttest concept map. The pretest took place at the beginning of the new project or when a new topic was introduced. The posttest was undertaken when the project or the topic that was dealt with was completed. Each student thus had to draw a concept map about the same core concept on two different occasions. Core concepts involved in the study were, for example, 'climate', 'safety', and 'sustainable energy'. Core concepts were chosen in consultation with the participating teachers who also provided information about what the students were expected to know about the core concept in the end and thus allowed the researchers to judge the relevance of the content of the maps created by the students. Students were instructed to construct a map of all their knowledge with respect to the concept. More specifically, they were asked to (1) note 20-40 concepts for themselves, (2) think about which concepts were related to each other in order to cluster them and the relative importance of the different concepts and (3) write down everything in a concept map which they thought was logical. The students were given an hour for this task. The teachers were provided with a protocol to instruct PVSE students on the creation of concept maps, and students were given a form on which to make the concept maps.

\section{Background variables}

The background variables of age, gender, PVSE sector and program and the type of education (PVSE or VET) were measured by means of a short student questionnaire. For subsequent analyses, a dummy variable was created for student gender $(0=$ Male, thus representing the baseline; $1=$ Female). An ordinal variable was created for the four PVSE programs (ranging from $0=$ Basic vocational program to $3=$ Theoretical program). Dummy variables were also created for the PVSE sector $(0=$ Care and Welfare; $1=$ Technology $)$ and for type of education $(0=$ PVSE; $1=$ VET $)$.

Data analysis

\section{Learning situations questionnaire}

Given that the learning situations questionnaire was expected to characterise the different learning situations in terms of various aspects of the two dimensions of competence-based 
education in accordance with earlier research using the questionnaire by De Bruijn et al. (2005), scales were constructed after administration of the questionnaire. As mentioned before, three content scales Type, Power and Customary were distinguished. Also, three guidance scales were distinguished, namely Strong Guidance, Total Guidance and Growth (De Bruijn and Overmaat 2002).

Like in the study of De Bruijn and Overmaat (2002), most scales were found to have sufficient reliability (see Table 2). The Total Guidance scale had a Cronbach alpha coefficient of 0.60. However, because Bland and Altman (1997) suggest that alpha values of 0.60-0.70 are sufficient for non-traditional instruments, it was decided to retain this scale for further analyses. As expected, and also in line with the study of De Bruijn and Overmaat (2002), a positive significant correlation was found between the Type and Power scales of the content dimension $(r=0.54 ; p=0.04)$. Negative significant correlations were found between both the Type and Power scales and the control variable Customary $(r=-0.51 ; p=0.05$ and $r=-0.72 ; p=0.00)$. Regarding the guidance dimension scales, no significant correlations between the Strong Guidance, Total Guidance and Growth scales were found.

The average scale scores were used to calculate a total score for the learning situation on the content and guidance dimensions. Next, the average content and guidance scale scores for a learning situation were compared to the average score for the entire group in order to classify all of the learning situations. Based on this comparison (see De Bruijn et al. 2005), situations were described according to a three-point scale. Each learning situation could thus be characterised as follows:
+- or -+
Low score on content dimension; low score on guidance dimension
+- or $-+\quad$ High score on content dimension; low score on guidance dimension; Low score on content dimension; high score on guidance dimension
$++$ High score on content dimension; high score on guidance dimension.

\section{Concept maps}

As the measurement of conceptual knowledge using concept mapping is quite complicated, we developed a three-phase procedure to analyse the concept maps. The procedure was derived from a study of the relevant research literature (Akinsanya and Williams 2004; Liu 2004; Mavers et al. 2002; Ruiz-Primo et al. 2001). The procedure to evaluate the general quality and development of the concept maps was tested in a pilot study.

In the first phase of the analysis, coders were supposed to get a thorough picture of several characteristics of students' concept maps. The pretest and posttest concept maps were analysed by hand, using criteria derived from the literature with regard to (1) points

Table 2 Descriptive statistics for each questionnaire scale

\begin{tabular}{lllllll}
\hline Scale & Number of items & Minimum & Maximum & $M$ & SD & $\alpha$ \\
\hline Type & 14 & 1.00 & 4.00 & 2.40 & 0.99 & 0.75 \\
Power & 14 & 1.31 & 2.92 & 2.18 & 0.46 & 0.86 \\
Customary & 14 & 1.23 & 3.00 & 1.96 & 0.48 & 0.85 \\
Strong guidance & 14 & 1.00 & 3.00 & 2.16 & 0.80 & 0.90 \\
Total guidance & 14 & 2.38 & 4.13 & 3.39 & 0.51 & 0.60 \\
Growth & 14 & 1.00 & 5.00 & 3.07 & 0.32 & 0.74 \\
\hline
\end{tabular}


of interest, (2) variables and (3) indicators (see Table 3). The points of interest derived from the literature were operationalised in variables that were linked to indicators that were directly applicable for the analysis of the maps. The variables and indicators were considered as criteria for the elaborateness and organisation of the maps. At this point in the analyses, however, only a small part of the concept maps was coded in this way in order to familiarise coders with the characteristics of a concept map and to prepare them for the second phase. In addition, PVSE teachers had provided information about the relevance and relative importance of particular concepts that students were anticipated to use in the maps prior to the creation of concept maps by the students. This was done in order to help the coders to assess the importance of the concepts used by the students.

In the second phase, the quality of the pretest and posttest concept maps was determined via an overall examination of the elaborateness and organisation for each of the concept maps. The elaborateness involved the number of concepts (i.e. nodes), links, layers, clusters and relevance of the concepts. The organisation of the concept maps was evaluated in terms of the relative importance of the concepts included, the types of connections and the clusters of concepts. Using the concept map, findings for all of the criteria (based on the variables and indicators) were combined to produce an overall picture of the quality of the

Table 3 Coding scheme for analysis of concept maps

\begin{tabular}{|c|c|c|c|c|}
\hline Phase & Points of interest & Variables & Indicators & Analysis \\
\hline \multirow{7}{*}{$\begin{array}{l}\text { Phase } \\
1\end{array}$} & \multirow[t]{3}{*}{ Concepts } & Elaborateness & Number of nodes & Counting \\
\hline & & Relevance & $\begin{array}{l}\text { Ratio between relevant } \\
\text { and irrelevant nodes }\end{array}$ & $\begin{array}{l}\text { Ratio between relevant and } \\
\text { irrelevant nodes }\end{array}$ \\
\hline & & $\begin{array}{l}\text { Relative } \\
\text { importance }\end{array}$ & $\begin{array}{l}\text { Position of a concept } \\
\text { relative to the core } \\
\text { concept }\end{array}$ & $\begin{array}{l}\text { Qualitative analysis using a three- } \\
\text { point scale (illogical-tolerably } \\
\text { logical-logical arrangement) }\end{array}$ \\
\hline & \multirow[t]{2}{*}{ Links } & $\begin{array}{l}\text { Number of } \\
\text { links }\end{array}$ & & Counting \\
\hline & & $\begin{array}{l}\text { Type of } \\
\text { connections }\end{array}$ & & $\begin{array}{l}\text { Categorisation: unconnected, } \\
\text { linear, one-centred, several- } \\
\text { centred, network }\end{array}$ \\
\hline & Depth & Stratification & Number of layers & $\begin{array}{l}\text { Maximum number of layers } \\
\text { counting from core concept }\end{array}$ \\
\hline & Content & $\begin{array}{c}\text { Clusters of } \\
\text { concepts }\end{array}$ & $\begin{array}{l}\text { Clusters with different } \\
\text { topics distinguished in } \\
\text { the concept map }\end{array}$ & $\begin{array}{l}\text { Counting plus categorisation/ } \\
\text { determination of relevance } \\
\text { of clusters }\end{array}$ \\
\hline $\begin{array}{l}\text { Phase } \\
2\end{array}$ & $\begin{array}{l}\text { Final judgement } \\
\text { (quality) }\end{array}$ & \multicolumn{2}{|c|}{ Judgement of quality of concept map } & $\begin{array}{l}\text { 1: Very poor organisation } \\
\text { of knowledge } \\
\text { 2: Poor organisation } \\
\text { 3: Neutral } \\
\text { 4: Good organisation } \\
\text { 5: Very good organisation }\end{array}$ \\
\hline $\begin{array}{l}\text { Phase } \\
3\end{array}$ & $\begin{array}{l}\text { Final judgement } \\
\text { (knowledge } \\
\text { development) }\end{array}$ & \multicolumn{2}{|c|}{$\begin{array}{l}\text { Judgement of knowledge development in } \\
\text { terms of elaborateness and organisation }\end{array}$} & $\begin{array}{l}\text { 1: Strong deterioration } \\
\text { of knowledge } \\
\text { 2: Slight deterioration } \\
\text { 3: No deterioration/no } \\
\text { improvement } \\
\text { 4: Slight improvement } \\
\text { 5: Strong improvement } \\
\text { of knowledge }\end{array}$ \\
\hline
\end{tabular}


concept map. Successively, this overall picture for all of the pretest and posttest concept maps was rated using a five-point Likert scale (see Table 3). A concept map was judged to reflect a 'very good quality of knowledge', for example, when a relatively large number of relevant concepts and links was used, the concepts were arranged in a logical manner (i.e. on the basis of the relative importance of the concepts and with elaborate connections), more important concepts were located closer to the centre of the concept map than less important concepts, and relevant clusters of concepts were distinguished (see Fig. 2). The criteria were given equal importance in the creation of the overall picture and were used to establish a more objective, well-founded final judgement about the quality of each concept map. It was decided to determine the overall quality of conceptual knowledge in the concept map as this overall picture was considered to be more representative of the quality of the conceptual knowledge than separate scores on various specific characteristics of the concept maps.

In the third phase, in order to judge the development of knowledge of the students, the quality of the pretest concept maps was compared to the quality of the posttest concept maps using the information gathered in the second phase of the analysis. Some of the criteria were then considered more important than others in order to create a clearer distinction between the quality of the student's pretest and posttest concept maps and thereby to gain more insight into the development of the quality of students' knowledge (in terms of elaborateness and organisation). More important criteria included the ratio of relevant to irrelevant concepts, the position of concepts relative to the centre of the map, types of connections and clusters of concepts. On the basis of pilot results, the elaborateness and number of links and layers in the concept maps were considered more stable and therefore less important or significant for evaluation of the development of the quality of the concept maps.

Inter-rater reliability (Cohen's Kappa) between two raters for both the judgement of the quality of the concept maps and for knowledge development together was 0.78 (based on 188 out of 1,179 judgements).

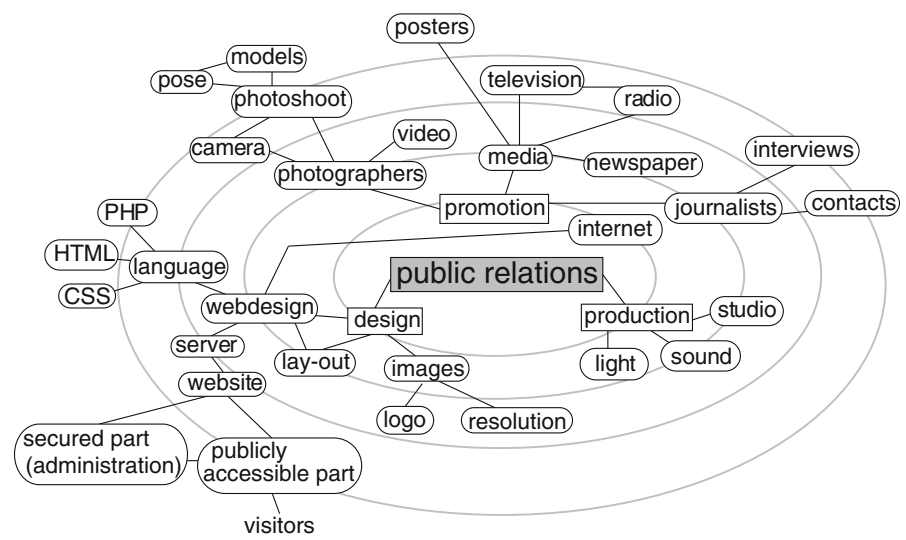

Fig. 2 Sample concept map about management tasks in a music hall (transformed because of the Dutch language used in the original paper-and-pencil version) 
Analysis of relationships between the learning environment, the quality of concept maps and background variables

Characteristics typifying the different learning situations, the quality of the concept maps and some background characteristics of the participants (i.e. age, gender, sectors in PVSE, PVSE programs and type of education: PVSE or VET) were analysed for relationships with each other in two ways. First, raw effects were established using correlations and $t$ tests. Second, a hierarchical multilevel analysis of variance (using MLwiN) was conducted to investigate which differences in the development of the students' knowledge could be explained by factors at the level of the learning situation and factors at the level of the student. An empty model was created to determine how much variance was located at the two levels. A model including all of the measured variables (i.e. classification of the learning situation, age, gender, sectors, programs and type of education) was tested thereafter. Those variables with a nonsignificant coefficient were then omitted from the model to produce a final model with only statistically significant variables. Effect sizes were computed (Snijders and Bosker 1999) as well as the amount of explained variance at the two levels of the model. In the following, the results for both the final model and the empty model are reported.

\section{Results}

Quality of the concept maps and development of student knowledge in relation to PVSE learning situations

The classifications of the learning situations provided a varied picture. Some of the learning situations clearly showed elements of competence-based education, while others showed no such elements but more traditional whole-class instruction. More specifically, five of the learning situations did not show many elements belonging to either the content or guidance dimensions of competence-based education; two of the learning situations showed elements of both dimensions; and seven learning situations showed either elements of the content dimension or the guidance dimension of competence-based education but not elements of both (see Table 4). ${ }^{1}$

The concept mapping technique clearly portrayed both the quality and development of student knowledge. The quality of the concept maps generated by the students at the posttest was significantly better in general than the quality of the concept maps generated at pretest $(t=-6.351 ; p=0.048$; also see Table 5).

For most of the students, their knowledge also developed from pretest to posttest as indicated by the different criteria in Table 3 . As can be seen from Table 6 , for most of the students, the conclusion can be drawn that the elaborateness and organisation of their knowledge improved or strongly improved $(N=150)$ or remained approximately the same $(N=62)$ during the period of study (see Table 6$)$.

\footnotetext{
1 Based on personal observation of the learning situations and informal conversations with experts, teacher trainers and teachers in this field by the first author and major researcher of this study, the implementation of the elements of competence-based education appeared to vary from relatively short projects, in which authentic contexts were used to promote meaningful learning, to complete changes in the school curriculum as a whole into, for example, so-called learning areas with different subjects integrated within a particular area.
} 
Table 4 Classification of learning situations and number of participants, of concept maps and of cases in which development of knowledge was measured

\begin{tabular}{|c|c|c|c|c|c|}
\hline \multirow[t]{2}{*}{ Classification } & \multicolumn{5}{|l|}{ Number } \\
\hline & $\begin{array}{l}\text { Learning } \\
\text { situations }\end{array}$ & Participants & $\begin{array}{l}\text { Concept maps } \\
\text { Pretest }\end{array}$ & $\begin{array}{l}\text { Concept maps } \\
\text { Posttest }\end{array}$ & $\begin{array}{l}\text { Cases in which development } \\
\text { of knowledge was measured }\end{array}$ \\
\hline-- & 5 & 233 & 166 & 161 & 104 \\
\hline$+-1-+$ & 7 & 488 & 277 & 207 & 140 \\
\hline++ & 2 & 91 & 49 & 49 & 44 \\
\hline Total & 14 & 812 & 492 & 417 & 288 \\
\hline
\end{tabular}

- - Low score on content dimension; low score on guidance dimension

+- or -+ High score on content dimension and low score on guidance dimension; low score on content dimension and high score on guidance dimension

++ High score on content dimension; high score on guidance dimension

Table 5 Quality of the concept maps at pretest and posttest along a five-point scale

\begin{tabular}{llllll}
\hline Testing & $N$ & Minimum & Maximum & $M$ & SD \\
\hline Pretest & 492 & 1.00 & 5.00 & 2.77 & 1.11 \\
Posttest & 417 & 1.00 & 5.00 & 3.06 & 1.06 \\
\hline
\end{tabular}

Relationships between development of student knowledge and the two dimensions of competence-based education

Our research population was different on a number of characteristics. Most importantly, the PVSE students were in learning situations which differed in the degree to which the elements of competence-based education had been adopted. In those learning situations which involved more characteristics of competence-based education, the PVSE students were found to score approximately equally highly on the development of knowledge scale as in those learning situations which involved fewer such characteristics (see Table 7). A relatively small but significant difference was found for the development of knowledge across the different learning situations when classified according to Table 4 and 6 ( $r=$ $-0.143 ; p=0.015)$. The less learning situations were classified as competence-based, the higher was the rate of development of knowledge.

Closer examination of the characteristics of the learning situations revealed some additional differences. With regard to the content dimension of the learning situations in general, a small significant difference in the development of knowledge was detected $(r=-0.137 ; p=0.020$; see Table 7). One of the variables which constitute the content dimension used to characterise the learning situations, namely, Type (or the degree to which the organisation of the learning situation could be typified as potentially powerful) was negatively related to the students' development of knowledge $(r=-0.175$; $p=0.003$ ). The content variable of Power (or the degree to which components considered powerful in advance were realised) did not relate significantly to the students' development of knowledge. And the control variable of Customary (or a learning situation with less powerful characteristics from the perspective of competence-based learning) also exerted a small negative influence on the development of knowledge $(r=-0.164 ; p=0.005)$. 
Table 6 Judged quality of concept maps and development of knowledge along a five-point scale

\begin{tabular}{|c|c|c|c|c|c|c|c|c|}
\hline \multirow[t]{2}{*}{ Criterion } & \multicolumn{2}{|c|}{ Learning situation } & \multicolumn{6}{|c|}{ Judged quality } \\
\hline & & & 1 & 2 & 3 & 4 & 5 & Total \\
\hline \multicolumn{9}{|l|}{ Concept maps } \\
\hline \multirow[t]{6}{*}{ Pretest } & -- & $\%$ & 24.1 & 27.7 & 29.5 & 18.7 & 0 & 166 \\
\hline & & $\mathrm{f}$ & 40 & 46 & 49 & 31 & 0 & \\
\hline & $+-1-+$ & $\%$ & 11.9 & 24.5 & 30.3 & 26.4 & 6.9 & 277 \\
\hline & & $\mathrm{f}$ & 33 & 68 & 84 & 73 & 19 & \\
\hline & ++ & $\%$ & 10.2 & 14.3 & 36.7 & 36.7 & 2.0 & 49 \\
\hline & & $\mathrm{f}$ & 5 & 7 & 18 & 18 & 1 & \\
\hline \multirow[t]{6}{*}{ Posttest } & -- & $\%$ & 8.1 & 28.1 & 30.6 & 36.2 & 3.1 & 160 \\
\hline & & $\mathrm{f}$ & 13 & 35 & 49 & 58 & 5 & \\
\hline & $+-1-+$ & $\%$ & 11.1 & 20.3 & 43.4 & 31.9 & 7.7 & 207 \\
\hline & & $\mathrm{f}$ & 23 & 42 & 66 & 60 & 16 & \\
\hline & ++ & $\%$ & 2.0 & 12.2 & 44.9 & 34.7 & 6.1 & 49 \\
\hline & & $\mathrm{f}$ & 1 & 6 & 22 & 17 & 3 & \\
\hline \multirow[t]{6}{*}{ Development of knowledge } & -- & $\%$ & 6.4 & 11.7 & 21.3 & 46.8 & 24.5 & 94 \\
\hline & & $\mathrm{f}$ & 6 & 11 & 20 & 44 & 23 & \\
\hline & $+-1-+$ & $\%$ & 13.6 & 21.4 & 24.5 & 22.9 & 6.4 & 140 \\
\hline & & $\mathrm{f}$ & 19 & 30 & 32 & 50 & 9 & \\
\hline & ++ & $\%$ & 0 & 22.7 & 22.7 & 47.7 & 6.8 & 44 \\
\hline & & $\mathrm{f}$ & 0 & 10 & 10 & 21 & 3 & \\
\hline
\end{tabular}

Number of students completing the concept maps was less than 812 because of absence, illness or incomplete data

-- Low score on content dimension; low score on guidance dimension

+- or -+ High score on content dimension and low score on guidance dimension; low score on content dimension and high score on guidance dimension

++ High score on content dimension; high score on guidance dimension

Table 7 Correlations between the development of students' knowledge and classifications of the learning situation

$* * p<0.01, * p<0.05$ $\overline{\text { Classification of learning situation } \quad \text { Correlation with development }}$ of knowledge

\begin{tabular}{lc}
\hline Content dimension & $-0.137^{*}$ \\
Type & $-0.175^{* *}$ \\
Power & 0.011 \\
Customary & $-0.164^{* *}$ \\
Guidance dimension & -0.040 \\
Strong guidance & -0.083 \\
Total guidance & 0.055 \\
Growth & $0.121^{*}$ \\
\hline
\end{tabular}

No statistically significant correlation was found between the general guidance dimension and the development of knowledge $(r=-0.040 ; p=0.496)$. The two guidance variables of Strong Guidance (the provision of systematic guidance, learning routes and tools) and Total Guidance (nine forms of guidance) did not relate significantly to the 
development of knowledge, while the Growth variable (which indicates different degrees of guidance depending upon the level of the students) had a small, positive and significant correlation with students' development of knowledge $(r=0.121 ; p=0.040)$.

In summary, the content dimension used to characterise the learning environments studied here appeared to be more important than the guidance dimension. Slightly more development of knowledge was found in learning situations with fewer characteristics of competence-based education than in those with more such characteristics. The provision of guidance in a manner which can be related to characteristics of competence-based education did not contribute to knowledge construction.

Relations between the development of student knowledge and background variables

Students who were in the upper grades (Grade 3 of PVSE or VET, 14-20 years) produced better concept maps at both pretest $(t=3.928 ; p=0.000)$ and posttest $(t=3.145$; $p=0.002$ ) than students in the lower grades (Grades 1 and 2, 12-14 years). The average scores at pretest were 2.61 for the lower grades and 3.00 for the upper grades. The average scores at post-test were 2.90 and 3.23, respectively. Older students were thus able to construct better concept maps than younger students but did not develop significantly more knowledge. When the PVSE and VET data were compared, the results again showed the older VET students producing better concept maps at pretest than the younger PVSE students $(t=4.414 ; p=0.000)$. There were no significant differences between PVSE and VET as far as the quality of the posttest and development of knowledge were concerned.

The pretest concept maps generated by students in the Technology sector were of a higher quality than those generated by students in the Care and Welfare sector $(t=$ $-6.269 ; p=0.000$; see Table 8). However, the development of knowledge was found to be stronger for the students in the Care and Welfare sector than for the students in the Technology sector $(t=4.331 ; p=0.000)$. In the Care and Welfare sector, the population of students was mostly female; in the Technology sector, the population was mostly male. When the data were analysed according to gender, the results showed the same picture as for the associated sectors. The quality of the concept maps generated by the boys at pretest was better than the quality of the concept maps generated by the girls at pretest $(t=2.076$; $p=0.038)$, but the girls showed more development of knowledge than the boys $(t=$ $-3.478 ; p=0.001)$.

No significant relationships were found between the educational program (mainly practice-oriented or theory-oriented) that students were in and the quality of the concept maps generated at either pretest or posttest. Furthermore, no significant differences in the students' development of knowledge were found for the different types of programs. That

Table 8 Mean scores on the concept maps according to sector and gender

\begin{tabular}{llllll}
\hline Concept maps & \multicolumn{2}{l}{ Sector mean } & & \multicolumn{2}{l}{ Gender mean } \\
\cline { 2 - 3 } & Care and welfare & Technology & & Female & Male \\
\hline Quality pretest & 2.16 & 3.09 & 2.68 & 2.89 \\
Quality posttest & 2.97 & 3.09 & 3.16 & 2.96 \\
Development & 3.98 & 3.10 & 3.60 & 3.11 \\
\hline
\end{tabular}


is, the students' knowledge did not become better organised or more elaborate in programs which were more practice-oriented or programs which were more theory-oriented.

Differences in the development of knowledge related to the level of learning situations and students

A multilevel analysis was conducted to investigate which differences could be explained by factors relating to the learning situations and the students themselves. In the empty model, the average score on the development of knowledge scale was 3.49 (range of 1-5). In the empty model, $80 \%$ of the total variance in students' development of knowledge was related to differences among the students; the remaining variance was related to differences in the learning situations.

In the explanatory model, the amounts of variance explained by the student variables and the level of the learning situation changed slightly (see Table 9). The explanatory model explained $3.11 \%$ of the variance in the students' knowledge development, and almost all of this pertained to the level of the learning situation. The outcomes of this model show a pattern in which the classifications of the learning situations (according to the score on the content and the guidance dimension) and student gender play a role in particular. A greater development of knowledge was detected in learning situations which possessed fewer characteristics of competence-based education. Furthermore, girls developed relatively more knowledge during the period under study than boys (an average of 0.20 more along the Likert scale). The effect sizes for these variables were relatively small with gender having the smallest effect, which was two-thirds of the effect size for classification of the learning situation. Despite the small amount of variance explained by the explanatory model, a statistically significant improvement in the fit of the model when compared to the empty model was nevertheless found with a ratio of $-2 * \log l i k e l i h o o d$ to $d f$ of 139.98 to $2(p<0.001)$.

It should be noted that most of the variance in both the empty and final explanatory models concerned student differences which were not measured in this research. For example, student preferences for particular types of learning activities could have played a major role. Differences at the level of the learning situation appeared to play less of a role in the development of knowledge. Nevertheless, there was a reduction of approximately one-sixth of the variance on account of learning situations in the explanatory model.

Table 9 Development of knowledge: Regression coefficients (significant at 0.05; standard deviations in parentheses) and variance components

\begin{tabular}{|c|c|c|c|c|}
\hline Statistic & Variables & Empty model & Explanatory model & Effect size \\
\hline & Constant & $3.49(0.13)$ & $3.84(0.31)$ & \\
\hline & Classification learning situation & & $-0.29(0.18)$ & 0.15 \\
\hline & Gender & & $0.20(0.10)$ & 0.09 \\
\hline \multirow[t]{3}{*}{ Variance } & Learning situation & $19.57 \%$ & $16.47 \%$ & \\
\hline & Student & $80.43 \%$ & $80.42 \%$ & \\
\hline & Explained & - & $3.11 \%$ & \\
\hline$-2 * \log ($ like $)$ & & $2,467.95$ & $2,334.97$ & \\
\hline Difference $\log (d f)$ & & & $132.98(2)$ & \\
\hline
\end{tabular}




\section{Conclusion and discussion}

The purpose of this study was to gain insight into the development of the knowledge of students in PVSE schools which differ in the manner and extent to which they have implemented characteristics of competence-based education. The focus of the study was on the elaborateness and organisation of the students' knowledge. In accordance with the results of a comparable study by De Bruijn et al. (2005), the investigated learning situations were indeed found to differ. In the majority of the learning situations $(n=7)$, some elements of either the content or guidance dimensions of competence-based education had been adopted. In five of the learning situations, virtually no such elements had been adopted. And only two of the learning situations could be described as mainly competencebased.

Regrettably, only small differences in the students' development of knowledge were found to occur across the different classifications of the learning situation. In line with other studies (Gijbels et al. 2008; Nijhuis et al. 2005), competence-based education appeared not to have the anticipated effect on student learning. Students developed slightly more knowledge in learning situations which contained fewer characteristics of competence-based education. The fact that the intricate process of implementation of competence-based education was still evolving in many of the investigated learning situations might have complicated students' knowledge development (Windschitl 2002).

The content dimension of the learning situations appeared to be a distinguishing characteristic for the development of knowledge. More specifically, the Type component of the content dimension, which indicates the degree to which the organisation of the learning situation could be typified as potentially powerful, appeared to negatively influence the students' learning slightly. It actually appeared that the organisation of the learning environment in a manner which is associated with competence-based education prompted less knowledge development. It is certainly possible that PVSE students find it more difficult to develop knowledge in learning situations which are less clear-cut. The manner in which learning tasks are integrated into competence-based learning situations, for example, typically creates fewer boundaries between subject areas; similarly, the adoption of authentic learning contexts can blur the boundaries between school and the real world. Perhaps PVSE students benefit from a more structured and, given their prior experiences in education, familiar organisation for their education. However, the presence of learning situation characteristics which were considered less powerful beforehand (i.e. characteristics considered more Customary or traditional) also negatively influenced students' knowledge development. The results of this research suggest that a balance between elements of competence-based education and more traditional forms of education could be most suited for the organisation of PVSE learning environments (Kirschner et al. 2006).

The results with regard to the guidance dimension of the learning situations provided some interesting information as well. In general, the guidance dimension did not make a significant difference for the development of knowledge. However, the specific component of Growth did influence the students' knowledge development significantly to some extent. Students developed more knowledge in learning situations where guidance was increasingly provided during the course of their educational careers. This positive correlation suggests that it might make sense to provide all forms of guidance during the entire educational trajectories of students and to carefully monitor their progress as well (Hattie and Timperley 2007).

Differences in the students' development of knowledge were also analysed with respect to student age, student gender, educational sector and educational program. Students in the 
upper grades of PVSE constructed better concept maps than students in the lower grades, but did not develop greater knowledge. Although the VET students also generated better pretest concept maps than PVSE students, they were comparable to the PVSE students when the development of the students' knowledge was considered. It is possible that a basic threshold level of prior knowledge is needed to generate well-organised concept maps as students must use this knowledge for the actual construction of a concept map. This basic knowledge thus has little influence on the subsequent elaboration or further organisation of the students' knowledge. The development of the concept maps generated by students in the Care and Welfare sector (mostly girls) was significantly stronger than the development of the concept maps generated by students in the Technology sector (mostly boys). This is possibly because of the type of knowledge in the Technology sector for which more complicated concepts, which are less amenable to representation in a logical manner than many other concepts, must nevertheless be comprehended and recalled. All the same, in accordance with other research on gender differences in school achievement (Van Langen et al. 2006), girls in the present study showed better knowledge development and were more able to remember critical concepts than the boys. Students in the more practice-oriented programs did not construct better concept maps than students in the more theoretical programs, and also the development of knowledge did not differ significantly across these groups. In the multilevel analysis, the explanatory model again showed that the classifications of the learning environments and student gender influenced the development of knowledge. The multilevel analysis also showed that most of the differences in the development of knowledge was explained by differences among the students. Nevertheless, approximately $20 \%$ of the variance occurred at the level of the learning situation, which can more effectively be influenced by teachers and curriculum developers (Scheerens 2000). In this research, the learning situation and, more specifically, the presence of characteristics of competence-based education indeed influenced the development of knowledge but not consistently in the direction expected.

Based on our experiences during the present research, the concept mapping technique appeared to be a suitable method for visualising the quality and development of students' knowledge in competence-based PVSE. Concept mapping is perhaps even more suited for this purpose than traditional testing as the structure of the students' knowledge (i.e. organisation and elaborateness) can be investigated as well (Novak 2002). The concept mapping technique also made it possible to investigate student knowledge across different subject areas, topics and schools, which would not have been possible using traditional tests. The arrangement of concepts and the constructed relations between them were indeed indicative of the quality of the students' knowledge. The criteria used to analyse the concept maps and their development, including the types of links, the depth of the concept maps and the clusters of concepts in the maps, proved useful for the rating of a large number of maps. However, the use of these criteria in conjunction with quantification of the data also produced a loss of information when compared to, for instance, an exhaustive analysis of the content of a small number of concept maps as is often done (e.g. Liu 2004). We nevertheless believe that the use of the present coding scheme provided as much information as possible about the quality of the concept maps, particularly in light of the large number of participants.

The results of the present study are possibly restricted, for example, by the nature of the sample. A limited number of schools was involved in the study and some of these schools had limited experiences with the implementation of elements of competence-based education. This could account for some of the disappointing results. Secondly, only teacher perceptions were taken into consideration in the study. In learning environments research, 
students' perceptions of the educational context are often studied because these perceptions appear to be valid and lead to higher amounts of variance explained in student outcomes (Fraser 1998). As stated earlier, in this study, teachers' perceptions of the learning situations that they created were chosen because relatively new learning environments were investigated. The study of students' perceptions of these learning environments might be a useful direction for future research, once the students are a little more familiar with the learning environment that they are in. Another suggestion for future research would be to investigate processes of knowledge development through, for example, paying attention to differences in students' cognitive learning activities conducted in different learning situations. Because of the generic nature of the concept mapping technique used to measure the development of the elaborateness and organisation of knowledge in this study, little attention could be paid to the actual process of learning and integrating new concepts.

Competence-based education is supposed to foster meaningful learning and therefore a better understanding of concepts and the relations between concepts. Competence-based learning environments can be described in terms of the manner in which the education is organised (i.e. a content dimension) and the manner in which the students are guided (i.e. a guidance dimension; De Bruijn et al. 2005). In the present research, the manner in which the learning situations were organised indeed had some influence on the students' development of knowledge, but not as expected. Learning situations with content characteristics of competence-based education only appeared to complicate the development of knowledge for PVSE students. Guidance characteristics, in contrast, seemed to slightly facilitate students' knowledge development. Guidance is indeed widely acknowledged to be an essential component of competence-based education (Moreno 2004). Schools which implement a form of competence-based education, therefore, should probably pay attention not only to the manner in which the curriculum is re-organised, but also to the provision of good student guidance. The provision of guidance within the context of competence-based education can possibly even be improved with the provision of more regular and diverse forms of guidance (Gibbs and Simpson 2004; Hattie and Timperley 2007). It is then possible that, under such guidance circumstances, the negative effects of the content components of competence-based education could disappear or be compensated for. Good guidance in relation to the development of knowledge and content of what has to be learned can make more explicit for students' knowledge and the relations between learning content or the core concepts to be learned (Entwistle and Peterson 2004; Kirschner et al. 2006). With regard to the content dimension of competence-based education, moreover, it is recommended that a balance be sought between elements of competence-based education and elements of more traditional forms of education when organising learning environments to foster the construction of knowledge and learning which is meaningful.

Open Access This article is distributed under the terms of the Creative Commons Attribution Noncommercial License which permits any noncommercial use, distribution, and reproduction in any medium, provided the original author(s) and source are credited.

\section{References}

Akinsanya, C., \& Williams, M. (2004). Concept mapping for meaningful learning. Nurse Education Today, $24,41-46$.

Ausubel, D. P. (1968). Educational psychology: A cognitive view. New York: Holt, Rinehart \& Winston.

Biemans, H., Nieuwenhuis, L., Poell, R., Mulder, M., \& Wesselink, R. (2004). Competence-based VET in the Netherlands: Background and pitfalls. Journal of Vocational Education and Training, 56, 523-538. 
Bland, J. M., \& Altman, D. G. (1997). Statistical notes: Cronbach's alpha. British Journal of Medical Practices, 314, 572-573.

Blumberg, P. (2000). Evaluating the evidence that problem-based learners are self-directed learners: A review of the literature. In D. Evensen \& C. Hmelo (Eds.), Problem-based learning: A research perspective on learning interactions (pp. 199-226). London: Lawrence Erlbaum.

Boekaerts, M., \& Simons, P. R. J. (2003). Leren en instructie: Psychologie van de leerling en het leerproces [Learning and instruction: Psychology of learners and the learning process]. Assen, The Netherlands: Van Gorcum.

Budd, J. W. (2004). Mind maps as classroom exercises. The Journal of Economic Education, 35(1), 35-46.

Buzan, T. (1991). The mind map book. New York: Penguin.

De Bruijn, E., \& Overmaat, M. (2002). Tussentijdse rapportage op verzoek van de PROO: Onderzoeksproject 'Intern rendement van krachtige leeromgevingen in het secundair beroepsonderwijs' [Internal yield of powerful learning environments in VET]. 's Hertogenbosch. The Netherlands: CINOP.

De Bruijn, E., Overmaat, M., Glaudé, M., Heemskerk, I., Leeman, Y., Roeleveld, J., et al. (2005). Krachtige leeromgevingen in het middelbaar beroepsonderwijs: Vormgeving en effecten [Powerful learning environments in vocational education and training: Design and effects]. Pedagogische Studiën, 82(1), 77-95.

De Corte, E. (2003). Designing learning environments that foster the productive use of acquired knowledge and skills. In E. De Corte, L. Verschaffel, N. Entwistle, \& J. J. G. Van Merriënboer (Eds.), Powerful learning environments: Unravelling basic components and dimensions (pp. 21-33). Oxford: Elsevier Science.

Dochy, F., Segers, M., Van de Bossche, P., \& Gijbels, D. (2003). Effects of problem-based learning: A meta-analysis. Learning and Instruction, 13, 533-568.

Entwistle, N. J., \& Peterson, E. R. (2004). Conceptions of learning and knowledge in higher education: Relationships with study behaviour and influences of learning environments. International Journal of Educational Research, 41, 407-428.

Eraut, M. (2004). Informal learning in the workplace. Studies in Continuing Education, 26, 247-273.

Fraser, B. J. (1998). Research synthesis on school and instructional effectiveness. In D. Gabel (Ed.), Handbook of research on science teaching and learning (pp. 483-541). New York: Macmillan.

Gathercole, S. E. (1998). The development of memory. Journal of Child Psychology and Psychiatry, 39(1), $3-27$.

Gibbs, G., \& Simpson, C. (2004). Conditions under which assessment supports students' learning. Learning and Teaching in Higher Education, 1, 3-31.

Gijbels, D., Coertjens L., Vanthournout, G., Struyf, E., \& Van Petegem, P. (2008). Over goede intenties en de weg naar de hel: nieuwe leeromgevingen en de (on)mogelijkheid om diepgaande leerstrategieën te bewerkstelligen [The road to hell: New learning environments and attempts to enhance students approaches to deep learning]. Paper presented at the Onderwijs Research Dagen 2008 Conference, Eindhoven, The Netherlands.

Guile, D., \& Young, M. (2003). Transfer and transition in vocational education: Some theoretical considerations. In T. Tuomi-Gröhn \& Y. Engeström (Eds.), Between school and work: New perspectives on transfer and boundary-crossing (pp. 19-38). Amsterdam: Pergamon.

Gulikers, J. T. M., Bastiaens, T. J., \& Martens, R. L. (2005). The surplus value of an authentic learning environment. Computers in Human Behavior, 21, 509-521.

Hattie, J., \& Timperley, H. (2007). The power of feedback. Review of Educational Research, 77(1), 81-112.

Kirschner, P. A., Sweller, J., \& Clark, R. E. (2006). Why minimal guidance during instruction does not work: An analysis of the failure of constructivist, discovery, problem-based, experiential, and inquirybased teaching. Educational Psychologist, 4(2), 75-86.

Könings, K. D., Brandt-Gruwel, S., \& Van Merriënboer, J. J. G. (2005). Towards more powerful learning environments through combining the perspectives of designers, teachers, and students. British Journal of Educational Psychology, 75, 645-660.

Linn, R., Baker, E. L., \& Dunbar, S. B. (1991). Complex performance-based assessment: Expectations and validation criteria (CSE Technical Report 331). Boulder, CO: University of Colorado.

Liu, X. (2004). Using concept mapping for assessing and promoting relational conceptual change in science. Science Education, 88, 373-396.

Mavers, D., Somekh, B., \& Resorick, J. (2002). Interpreting the externalized images of pupils' conceptions of ICT: Methods for the analysis of concept maps. Computers \& Education, 38, 187-207.

Merrill, M. D. (2002). First principles of instruction. Educational Technology Research and Development, $50,43-59$

Moos, R. H. (1979). Evaluating educational environments: Methods, procedures, findings and policy implications. San Francisco: Jossey-Bass. 
Moreno, R. (2004). Decreasing cognitive load for novice students: Effects of explanatory versus corrective feedback in discovery-based multimedia. Instructional Science, 32, 99-113.

Nijhuis, J., Segers, M., \& Gijselaers, W. (2005). Influence of redesigning a learning environment on student perceptions and learning strategies. Learning Environment Research, 8, 67-93.

Novak, J. D. (2002). Meaningful learning: The essential factor for conceptual change in limited or inappropriate propositional hierarchies leading to empowerment of learning. Science Education, 86, 548-571.

Pintrich, P. R., Marx, R. W., \& Boyle, R. A. (1993). Beyond cold conceptual change: The role of motivational beliefs and classroom contextual factors in the process of conceptual change. Review of Educational Research, 63, 167-199.

Ruiz-Primo, M. A., Schultz, S. E., Li, M., \& Shavelson, R. J. (2001). Comparison of the reliability and validity of scores from two concept-mapping techniques. Journal of Research in Science Teaching, 38, 260-278.

Scardamalia, M., \& Bereiter, C. (2006). Knowledge building: Theory, pedagogy, and technology. In K. Sawyer (Ed.), Cambridge handbook of the learning sciences (pp. 97-118). New York: Cambridge University Press.

Scheerens, J. (2000). Improving school effectiveness. Paris: UNESCO.

Schelfhout, W., Dochy, P., Janssens, S., Struyven, K., \& Gielen, S. (2006). Towards an equilibrium model for creating powerful learning environments: Validation of a questionnaire on creating powerful learning environments during teacher training internships. European Journal of Teacher Education, 29, 471-503.

Sluijsmans, D. M. A., Straetmans, G. J. J. M., \& Van Merriënboer, J. J. G. (2008). Integrating authentic assessment with competence-based learning in vocational education: The Protocol Portfolio Scoring. Journal of Vocational Education \& Training, 60, 159-172.

Snijders, T. M., \& Bosker, R. J. (1999). Multilevel analysis: An introduction to basic and advanced multilevel modeling. London: Sage.

Sweller, J., \& Sweller, S. (2006). Natural information processing systems. Evolutionary Psychology, 4, 434-458.

Telli, S., Den Brok, P. J., \& Cakiroglu, J. (2007). Students' perceptions of science teachers' interpersonal behaviour in secondary schools: Development of the Turkish version of the Questionnaire on Teacher Interaction. Learning Environments Research, 10, 115-129.

Trautwein, U., \& Lüdtke, O. (2009). Predicting homework motivation and homework effort in six school subjects: The role of person and family characteristics, classtroom factors, and school track. Learning and Instruction, 19, 243-258.

Trigwell, K., \& Prosser, M. (1991). Improving the quality of student learning: The influence of learning context and student approaches to learning on learning outcomes. Higher Education, 22, 251-266.

Trochim, W. M. K. (1989). An introduction to concept mapping for planning and evaluation. Evaluation and Program Planning, 12, 1-16.

Van der Sanden, J. M. M. (2004, March). Ergens goed in worden: naar leerzame loopbanen in het beroepsonderwijs [Becoming competent: Towards rich learning careers in vocational education]. Inaugural speech presented at Fontys University of Applied Sciences, Eindhoven, The Netherlands.

Van Grinsven, L., \& Tillema, H. (2006). Learning opportunities to support student self-regulation: Comparing different instructional formats. Educational Research, 48(1), 77-91.

Van Langen, A., Bosker, R., \& Dekkers, H. (2006). Exploring cross-national differences in gender gaps in education. Educational Research and Evaluation, 12, 155-177.

Van Merriënboer, J. J. G., \& Paas, F. (2003). Powerful learning and the many faces of instructional design: Towards a framework for the design of powerful learning environments. In E. DeCorte, L. Verschaffel, N. Entwistle, \& J. J. G. Van Merriënboer (Eds.), Powerful learning environments: Unravelling basic components and dimensions (pp. 3-20). Oxford, UK: Elsevier Science.

Vosniadou, S. (2007). The cognitive-situative divide and the problem of conceptual change. Educational Psychologist, 42(1), 55-66.

Watzlawick, P., Beavin, J., \& Jackson, D. (1967). Pragmatics of human communication. New York: W.W. Norton.

Wesselink, R., Biemans, H. J. A., \& Mulder, M. (2007, September). Perceptions of teachers and students participating in competence-based VET. Paper presented at the European Conference on Educational Research 2007, University of Ghent, Belgium.

Windschitl, M. (2002). Framing constructivism in practice as the negotiation of dilemmas: An analysis of conceptual, pedagogical, cultural and political challenges facing teachers. Review of Educational Research, 72, 131-175. 
Wubbels, T., Brekelmans, M., Den Brok, P., \& Van Tartwijk, J. (2006). An interpersonal perspective on classroom management in secondary classrooms in the Netherlands. In C. Evertson \& C. Weinstein (Eds.), Handbook of classroom management: Research, practice, and contemporary issues (pp. 1161-1191). Mahwah, NJ: Lawrence Erlbaum Associates. 